\title{
Beobachtungen auf dem astrophysikalischen Observatorium in OGyalla.
}

Comet $1886 \ldots$ (Fabry).

Nach eingelaufenem Bericht über die Entdeckung des Cometen wurde dieser sofort am ersten klaren Abend eingestellt und spectroskopisch und photometrisch beobachtet.

I 885 Dec. 9. Comet sehr schwach. Im Spectroskop zeigte er ein äusserst schwaches continuirliches Spectrum, in welchem man die Farben nur mit der grössten Mühe unterscheiden konnte.

Herr Dr. von Kövesligethy machte am $254^{\mathrm{mm}}$ Refractor eine photometrische Vergleichung mit dem Stern DM. $+20^{\circ} 43$, $9 \cdot 5$. Die Beobachtung ist mit einem neutralen Glaskeil ausgeführt worden, dessen Transmissionscoefficient bislang aus Abblendungsversuchen $\mathrm{zu} \log p=-0.6608$ bestimmt wurde.

Die Abblendung wurde jedoch nur soweit getrieben, dass die einzelnen Endresultate in $p$ nicht erheblich varïrten. Das Messungsresultat ergiebt:

1885 Dec. $97^{\mathrm{h}} 0^{\mathrm{m}} \log \left(\right.$ Int. $\left.\frac{\text { Comet }}{\text { Stern }}\right)=-1.825$.

Dies Resultat ist auch wegen grosser Schwäche des Cometen etwas unsicher.

I $88{ }_{5}$ Dec. $276^{\mathrm{h}} 30^{\mathrm{m}}$. Der Comet ist scheinbar schwächer geworden, zeigt eine hübsche parabolische Coma, in deren Brennpunkt augenscheinlich der Kern liegt. Die Richtung ist NW.

$$
\text { Comet r } 886 \ldots \text { (Barnard). }
$$

${ }_{1} 885$ Dec. $276^{\mathrm{h}} 50^{\mathrm{m}}$. Der Comet ist recht schwach, sein Aussehen ist ziemlich kreisrund mit hellem Kerne. Im Spectroskop konnte man bloss ein ebenso schwaches Spectrum bemerken, wie dies beim Cometen Fabry der Fall war.

$$
\text { Nebel DM. }+11 \% 4577=\text { G. C. } 4670 \text {. }
$$

I 886 Jan. $46^{\mathrm{h}} 45^{\mathrm{m}}$. Beim Aufsuchen des Cometen Brooks stiess ich zufällig auf diesen schönen Nebel, welchen dann Dr, von Kövesligethy am Glaskeilphotometer beobachtet und mit dem Stern DM. +11 ${ }^{\circ} 45^{8} 3$, 6\%" ver. glichen hat:

$$
1886 \text { Jan. } 46^{\mathrm{h}} 45^{\mathrm{m}} \quad \log \left(\text { Int. } \frac{\text { Nebel }}{\text { Stern }}\right)=-0.763
$$

Der Nebel zeigt im Spectroskop ein schönes con. tinuirliches Spectrum.

\section{Neuer Stern bei $\chi^{1}$ Orionis.}

I 885 Dec. 27. Der Stern gehört zum Typus IlIa der Vogel'schen Spectraltypen. Das Spectrum ist recht hell und man bemerkt zwei starke Banden in Roth, die $D$ Linie, der eine helle Linie $\left(D_{3}\right)$ folgt, als Begrenzung einer Bande, hierauf zwei breite gleichförmig verwaschene Banden, nach diesen folgt abermals eine helle Linie, welche weniger brechbar ist als $F$, hierauf folgt $F$, und noch drei sehr breite Banden im Blau, welche beinahe ganz zusammen fliessen.

Herr Dr. von Kövesligethy hat am $162^{\mathrm{mm}}$ Refractor an diesem Sterne photometrische Vergleichungen angestellt, und zwar hat er die Nova mit DM. + $19^{\circ} 1186,5^{\mathrm{m}} \cdot 6$, verglichen und folgende Resultate erhalten:

Dec. 27. Höhe über Horizont $6 \mathrm{I}^{\circ} ; \log \frac{\text { Nova }}{\text { Stern }}=0.29^{2}$

$$
\begin{aligned}
& \text {, 28. \ }>59.6 ; \log \frac{\text { Nova }}{\text { Stern }}=-0.0 \mathrm{I} 8 \\
& \text { Jan. 3. " } \quad \Rightarrow \quad 5^{8} ; \log \frac{\text { Nova }}{\text { Stern }}=-0.368
\end{aligned}
$$

Die Farbe der Nova ist sehr tief orange, viel tiefer als $\alpha$ Orionis. Im monochromatischen Lichte würde seine Farbe etwa der Wellenlänge von $\alpha$ im Sonnenspectrum ent.

\begin{tabular}{|c|c|c|c|c|}
\hline Date & AnnArb. M.T & $\alpha$ app. & $\delta$ app. & $\log p . \angle$ \\
\hline 1882 & & & & \\
\hline May 17 & $10^{\mathrm{h}} 27^{\mathrm{m}} 26^{\mathrm{s}}$ & $2^{\mathrm{h}} 10^{\mathrm{m}} 27^{\mathrm{s}} \cdot 45$ & $+70^{\circ} 44^{\prime} 59^{\prime \prime} 7$ & 0.91 \\
\hline 22 & I $1 \quad 16 \quad 2$ & $\begin{array}{lll}3 & 18 & 53.63\end{array}$ & +64520.6 & 0.92 \\
\hline 23 & $\begin{array}{lll}x & 21 & 50\end{array}$ & $\begin{array}{lll}3 & 28 & 38.83\end{array}$ & +623148.5 & 0.932 \\
\hline
\end{tabular}
sprechen.

von Konkoly.

Meridian Observations of Comets.

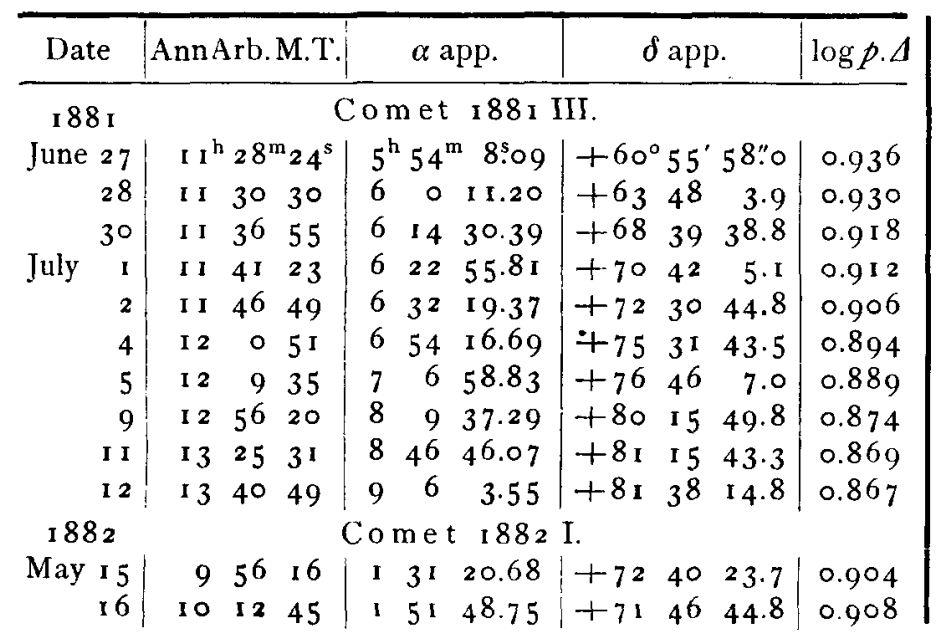

May 16. Through clouds, not very good.

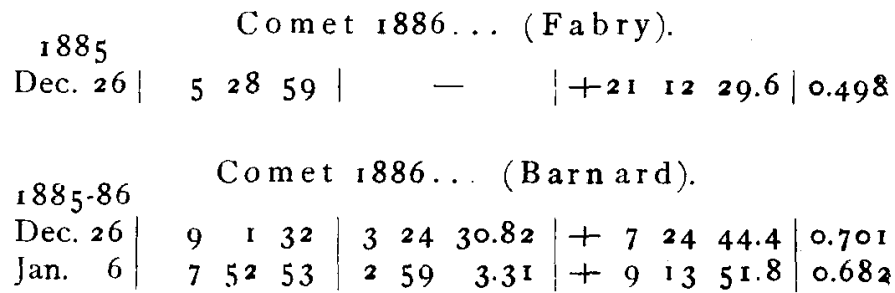

